\title{
O Poder Monádico
}

\author{
Hugo Leal* \\ * Instituto Superior de Ciências Sociais e Políticas - Universidade de Lisboa, Portugal
}

\begin{abstract}
Resumo
Partindo de uma questão simples - como se justifica a resiliência política do indivíduo perante a pressão para a conformidade exercida sobre ele pelo grupo? - o autor propõe uma reformulação do conceito essencial de Tempo e da sua interpretação pelo Homem e uma recuperação do conceito leibniziano de mónada. Defende que o Tempo é antropologicamente entendido sob três formas: a greística, relativa aos agregados; a idística, onde se situa a temporalidade individual; e a lógica, em que se criam narrativas de sentido, incluindo as políticas. Em cada uma delas é imanente uma forma de poder, sem que nenhuma se possa superiorizar às restantes. Por essa razão, o poder monádico, irredutível e visto como uma expressão essencialista do poder individual, não encontra sentido na subjugação ao poder coletivo.
\end{abstract}

Palavras-chave: tempo; Leibniz; Bergson; poder monádico

\begin{abstract}
Engaging in a simple question - how to justify the individual's political resilience under the pressure for conformity exercised over him by the group? - the author proposes a new approach to the fundamental concept of Time and to its interpretation by Man and a retrieval of the leibnizian concept of monade. The article argues that Time is anthropologically understood under three forms: the greistical one, concerning aggregates; the idistical, where we can place individual temporality; and the logical form, where meaningful narratives are created, including the political ones. To each of them a form of power is inherent, without superiority of one over the others. Due to that, monadic power, unyielding and seen as an essentialist expression of individual power finds no sense in subjugating to collective power.
\end{abstract}

Keywords: time; Leibniz; Bergson; monadic power 


\section{Introdução}

O indivíduo é o corpo do paradoxo na política. Não há política sem indivíduo, no geral, mas o indivíduo, em particular, é incomensurável pela política, e mantém-se como uma entidade tão abstrata como, por exemplo, «povo» ou «sociedade». Apesar de o mundo moderno ser, sobretudo, a epopeia da sua descoberta (Habermas, 2005, pp. 17-8), o indivíduo continua a ser um auctor desprovido de autoridade política ${ }^{[1]}$, detentor, na legitimação dos regimes, de um poder soberano de jure, mas não de facto.

Aceitamos a relação problemática entre o indivíduo e o grupo como um facto consumado e inevitável, sem pôr em causa a sua razoabilidade. No entanto, a natureza dessa relação não é inquestionável. Se o grupo é necessário ao indivíduo e o indivíduo necessário ao grupo, por que razão não se conforma totalmente o indivíduo à sua natureza gregária? Mais importante ainda é a questão que se coloca como orientadora deste estudo: como se justifica a resiliência do indivíduo perante a contante pressão do grupo, e perante a desproporção de forças nessa relação? Por que razão não encontra o indivíduo razões suficientes para (digamos assim) se render e se apaziguar?

Acreditamos que a resposta a este problema só não está compreendida porque, da mesma forma que se acostumou à luta entre a parte e o todo, o Homem deixou de questionar outro elemento primordial: o Tempo.

Autores como Edmund Husserl e Henri Bergson legaram-nos ideias fundamentais para conjugarmos indivíduo, mundo e tempo. Serão parte importante da revisão crítica deste trabalho, que, baseando-se numa metodologia interpretativa, pretende clarificar a relação entre o ser individual e os grupos em que este se integra, encontrar a raiz da sua autoridade, enquadrá-la logicamente com a lógica política e abrir espaço para uma compreensão mais profunda desse poder individual a que chamaremos monádico, baseando-nos no conceito de mónada originalmente proposto por Leibniz.

\section{Mundo e Mónada - A Coincidência Temporal}

Que existe um poder imanente no mundo é um facto inquestionável. O poder, na sua essência, é o que diferencia o ser do não-ser, e a prova do poder no mundo é a própria existência do mundo.

Até Foucault, os politólogos aceitaram, grosso modo, a distinção tradicional feita entre força e poder, e a ideia de que a política começava precisamente na fronteira entre a força bruta, coerciva, e o poder da palavra, persuasivo. Com Foucault ganha relevância a ideia do poder relacional, como criação espontânea a partir da coexistência entre seres humanos, um poder reticular, orgânico e emergente.

1. Por auctor, que significa, na sua origem, condutor, devemos entender aquele que detém um poder próprio, natural, original e exclusivo, aquele com a capacidade de saber de si e da sua vida, e por autoridade, consequentemente, esse poder real de decidir sobre o seu destino numa medida justa e, logo, politicamente aceitável 
A insuficiência que encontramos nestas duas perspetivas diferentes do poder resulta, quanto a nós, de um entendimento insuficiente do elemento «mundo», demasiado materialista na politologia tradicional, demasiado humanizada e individualizada em Foucault, ainda que, neste, mais próxima daquilo a que chamaremos poder monádico.

É preciso, para entender o que é «o mundo», dar um passo atrás em relação ao antropocentrismo e abstrair da realidade o que teríamos de encontrar para ter «um mundo»: um campo de possibilidade (em que o poder tenha um contexto de expressão), de agentes (ou entidades com propriedade perante o poder); heterogeneidade (sem a qual o poder de agentes não-idênticos não seria nem exprimível nem necessário); uma relação sistémica entre esses agentes (suficiente para solicitar a coerência no campo de possibilidade); e um código de procedimentos dos agentes que permita um ordenamento intrínseco ao campo de possibilidade.

O poder seria, assim, entendido como a positividade dinâmica de um contexto de realidade pela ação de agentes heterogéneos suficientemente relacionados e mutuamente inteligíveis, reconhecível por oposição à não-existência. Como conceção básica coerente de mundo, contudo, bastaria defini-lo como um plano simultâneo de heterogeneidade convergente.

O Tempo, que é a condição final sobre o Homem, deve ser visto como o campo de possibilidade para o mundo humano, de tal forma que esse mesmo Homem, mais do que apenas um animal temporal, pode ser considerado como um animal de simultaneidade: o que permite um mundo é a coexistência numa temporalidade percetível - e não apenas no espaço-tempo.

\section{A Polissemia de «Tempo»}

No seu percurso até ao indivíduo e à liberdade, Henri Bergson depara-se com o problema do tempo e encontra o conceito de duração (la durée). Nele nos deparamos com a requisição do tempo para o sujeito e com a apologia da intuição como poder validador da realidade.

«Habitualmente, quando falamos de tempo, falamos da medição da duração, e não da duração em si mesma», escreve Bergson. «Mas esta duração que a ciência elimina é o que sentimos e vivemos. (...) [A duração é] uma continuidade interior pura, não-adulterada, uma continuidade que não é unidade nem multiplicidade, e que não se encaixa nas nossas categorias de pensamento» (Bergson, 1946, p. 11)

Mais à frente reconhece que o entendimento da duração só é possível através de «uma intuição metafísica, que consiga seguir as ondulações do real. (...) Essa intuição estende-se sobre toda a duração interna. Compreende uma sucessão que não é uma justaposição mas um crescimento a partir de dentro, um prolongamento do passado para um presente que já se está a fundir no futuro. Será uma visão direta da mente pela mente - sem intervenções, sem refração pelo prisma de que uma faceta é o espaço e a outra a linguagem. Em vez de 
estados contíguos a estados, que se tornam em palavras em justaposição a palavras, teríamos aqui a indivisível e como tal substancial continuidade do fluxo da vida interior. A intuição significa, então, em primeiro lugar consciência, mas consciência imediata, uma visão dificilmente distinguível do objeto visto, um conhecimento que é contacto e mesmo coincidência - e depois uma consciência prolongada, pressionando o limite de um inconsciente que abre caminho e que resiste.» (Bergson, 1946, p. 34)

Entre o poder subjetivo e o seu reconhecimento, contudo, encontram-se os limites do entendimento humano:

«A duração é sempre expressa em termos de extensão; os termos em que designamos o tempo são emprestados da linguagem do espaço. Quando evocamos o tempo, é o espaço que sempre responde à nossa chamada. (Bergson, 1946, p. 12) [Parece que] uma das funções da estrutura do entendimento humano é precisamente a de mascarar a duração, ou como movimento ou como mudança.» (Bergson, 1946, 13) Mas «os momentos de tempo e as posições do móvel são apenas retratos que o nosso entendimento tirou da continuidade do movimento e da duração. (Bergson, 1946, p. 14) (...) Como podemos senão ver que a essência da duração é o fluxo, e que o fixo lado a lado com o fixo nunca constituirá nada que tenha duração? Não são os estados, simples retratos que tirámos uma e outra vez no curso da mudança, que são reais; pelo contrário, é o fluxo, a continuidade da transição, é a mudança em si mesma que é real. Esta mudança é indivisível; é, mesmo, substancial». (Bergson, 1946, p.15)

Bergson sugere mesmo uma osmose entre possibilidade e realidade realizada dentro do próprio sujeito:

"A sucessão entendida como tal nada adiciona; pelo contrário, tira; marca um défice; revela uma fraqueza da nossa perceção, que é forçada por essa fraqueza a dividir o filme imagem a imagem em vez de o capturar no seu agregado. Em resumo, o tempo assim considerado mais não é que um espaço em ideia onde imaginamos existirem em linha todos os eventos passados, presentes e futuros, e, mais ainda, que evita que eles apareçam numa única perceção: o desenrolar da duração seria esta mesma incompletude, a soma de uma quantidade negativa. (Bergson, 1946, p.17) (...) Esta conceção do tempo não permite entender um ato que seja completamente novo (pelo menos interiormente) e que de forma alguma poderia existir, nem mesmo sob a forma de um puramente possível, antes da sua realização. No entanto, esta é a verdadeira natureza de um ato livre. É a diferença entre a evolução e o surgimento, entre o radicalmente novo e o rearranjo do pré-existente. (...) Considerando a duração como uma evolução criativa, existe uma criação perpétua de possibilidade e não apenas de realidade.» (Bergson, 1946, p.19)

Com Bergson percebemos a complexidade da transição desse tempo a que chamaremos idístico para a sua conceção lógica (ver segmento seguinte), já assumida, antes disso, em Edmund Husserl. No princípio do século xx, Husserl aborda a questão do tempo «no mónada», colocando-o como primeiro elemento objetivo na constru- 
ção fenomenológica desse ser "próprio» (Husserl, 2013, p. 107). Para Husserl o tempo encontra-se presente também na imaginação, que tem a sua temporalidade particular, tal como a representação dos fenómenos na memória, que transforma sensações já tidas em eventos presentes, ou re-apresentados (Husserl, 2008, pp. 252-261).

A «consciência do tempo» e a sua relação aparentemente paradoxal com o «tempo objetivo» — «(...) O tempo detém-se e, no entanto, flui. No fluxo do tempo, no contínuo afundamento no passado, um tempo idêntico-objetivo absolutamente fixado, não-fluente, é constituído. Esse é o problema.» (Husserl, 2008, pp. 261-2) - apresentam claramente o multiversalismo a que o tempo não pode escapar e a sua dimensão individual para além da comum, material. É nessa temporalidade «extra-temporal» que se torna possível a individualidade (Husserl, 2008, pp. 262-4). A essência do indivíduo é a sua posição intencional no tempo, sendo este «não é uma forma de consciência mas a forma de qualquer objetividade possível». "O tempo», conclui o autor alemão, «é a forma necessária da objetividade individual e nada tem a ver com a subjetividade contingente» (Husserl, 2008, pp. 270-1).

Chegamos, desta forma, ao conceito leibniziano de mónada, esse «autómato incorpóreo, distinto, com qualidades próprias e aptas à mudança». Como unidade substancial irredutível, cada mónada é, também, original, autoral e produtor de mudança em vez de produzido por ela (Leibniz, 2016, p. 44).

A intenção metafísica de Leibniz no seu desenho do mónada impede-o de o considerar equivalente ao indivíduo ou a um ponto, mas o mónada tem, de facto, uma dimensão pontual, como algo que, sendo puramente eidético, não tem uma posição espacial. O problema resolve-se se esse ponto se situar no tempo, e não no espaço. A localização temporal própria e exclusiva do mónada torna-se, dessa forma, inteligível, e abre a porta à compreensão do seu poder autónomo.

O mónada não é o mesmo que indivíduo porque não é uma parte, mas uma não-parte que se move num plano de não-circunscrição e não é composta a partir do todo, antes determina a sua composição (Leibniz, 2016, p. 39). Nesta definição essencialista encontramos a ligação entre mónada e a perspetiva da primeira pessoa (Correia, 2012, pp. 17-20), que é a propriedade que distingue, verdadeiramente, uma entidade de outra. É diante dessa ligação que encontramos a dimensão politológica do mónada: permitindo distinguir o «eu» e a sua razão pessoal a partir da sua «apetição» própria (Leibniz, 2016, p. 42), estabelece o ponto de autonomia.

\section{Greística, Idística e Lógica: o Poder Tridimensional}

Em síntese, há poder onde há possibilidade; onde há Homem há tempo, e só porque há tempo; e as conceções humanas do real são constituídas sobre a temporalidade. Por tempo devemos entender, sucintamente, campo de consequencialidade, uma vez que a sua própria condição ontológica é a daquilo a que podemos chamar preenchimento (Reis, 2007, pp. 781 e segs.). O tempo só o é quando é locus de algo que não está sujeito à intransitabilidade - em que na existência de $a$ esteja implícita também, necessariamente, a possibilidade de $a$ '. Tudo o que é possível, para o Homem, é 
temporalizável, o poder é sempre uma intervenção no tempo e, como tal, o Homem entende o poder como uma imanação da temporalidade. Há poder onde há tempo. Antropologicamente, o tempo é percebido como uma síntese de elementos greísticos, idísticos e lógicos.

\subsection{Greísmos $^{[2]}$}

Por greísmo entendemos uma linearidade do tempo em que este é percebido como uma sequência dependente da autodeterminação - ou seja, em que um evento ' $y$ ' decorre de um evento ' $x$ ' e percorre uma linha pré-determinada para um evento ' $z$ '. Esta interpretação do tempo encontra-se na origem da visão naturalista do mundo, segundo a qual todas as coisas temporais obedecem a uma ordem regenerativa consequente e hermética que se reflete, por exemplo, nas abstrações nascer, viver e morrer.

A ideia fundamental do greísmo é a necessidade: um determinado ponto da realidade temporal relaciona-se necessariamente com outro e tem absoluta necessidade da existência dele, resultando a ação de um da ação do outro, e agindo ambos por uma informação comum de que não podem divergir. A observação greística do mundo permite uma caracterização desse mundo como universo - como única versão possível de uma realidade - e diz-nos por que razão determinado Universo é de determinada forma. A conceção mais aproximada à compreensão greística é a da physis clássica, na qual tudo o que se inicia retorna a um ponto inicial. A física é inerentemente absoluta.

Na visão greística o tempo é homogéneo e concretizar-se-ia numa unidade total, pelo que tudo tende para a simplificação informativa e para a uniformidade. $\mathrm{O}$ antagonismo, no tempo greístico, não é uma oposição irremediável de identidades, mas a irremediável identificação de opostos, compreensível pela premissa de existência de uma ordem mediadora hegemónica que determina que a relação de diversos se processe de uma forma e não de outra.

A circularidade greística (o eterno retorno), que é uma marca eidética da conceção física helenista do cosmos (Guthrie, 1962), permite uma divergência em espiral da consequencialidade, que é coerente com a dinâmica, mas não uma extroversão ou uma heterogeneidade substancial. Continua a ser uma dinâmica cingida a uma lógica causal que comporta qualquer tipo de complexidade. O greísmo é, assim, auto-suficiente.

O poder entendido greisticamente é percebido como uma relação de agregação compulsiva e inevitável, teleológica, de todos os elementos possíveis, pela objetivação do tempo: o tempo é um meio, e o agregado (o corpo, a tribo, a polis, o Estado) o objetivo. É um tempo corporal, materializável e orgânico, mesmo que o encaremos, como Plotino, como um movimento da alma do Universo e enquanto substrato do movimento e da matematização (Reis, 2007, pp. 87-114).

2. Grei, do latino grex, que significa rebanho (em grego, gargara é multidão) permite-nos atingir o sentido de agregação implícito às relações greísticas de poder. 


\subsection{Idísmos $^{[3]}$}

Perante os greísmos que constituem a normalidade filosófica no Ocidente, a idística é a manifestação do paradoxo. Idisticamente, no início está o ponto, que é a identidade incondicional: uma unidade abstrata, que em nenhum lado existe, mas sem a qual nada existe. Sem pontualidade não há posição; não há início, nem fim; não há norma, não há reta, logo, não há desenho, não há desígnio; não há futuro nem passado, porque não há referência. Sem o ponto (que existe mas não é), não há realidade.

A política não existe sem o indivíduo; mas quando se assume como uma derivação direta do greísmo torna-se no processo de homogeneização da individualidade. O indivíduo é origem da entropia, e, como tal, constitui a incerteza e a contraversão da ordem aparente.

Uma vez que a única forma de entender o tempo é fixando-o numa posição, o Homem abstrai o ponto como unidade mínima possível. A irredutibilidade monádica faculta à Lógica um objeto de operacionalidade que lhe permite a instituição de relações de poder. O tempo idístico é pontual, sem forma, distinto da res extensa (B. Espinosa, 1992, p. 122), mas representável, permitindo a linha, a geometria, o plano e, enfim, a constituição de uma ordem de poder.

O conceito de mónada só é inteligível, contudo, pela negação: um mónada é algo que não é outro mónada, determinando essa ipseidade a existência de um outro. Essa premissa gera a possibilidade de qualquer diferença: tudo é possível, mesmo perante a prova (greística) em contrário. O elemento genético da realidade (qualquer real é possível) constitui a condição do paradoxo.

$\mathrm{O}$ atributo efetivo do mónada é a visão na primeira pessoa: o poder de vivenciar o mundo a partir de um ponto exclusivo e próprio, por oposição à comunhão da «visão na terceira pessoa» (Correia, 2012, pp. 17-20), que é não apenas a condição necessária à evidência fenomenológica (Beyer, 2016) como aquilo que diferencia a idística da greística, tornando-a não-decorrente, mas equivalente em poder.

A essência idística é a intransponibilidade do fosso entre a primeira e a terceira pessoa, situando-se para cá desse fosso a propriedade no tempo, não como um mero ter, mas enquanto um poder-ter que é um ser-se (ownness).

A propriedade é a definição, em si mesma, de heterogeneidade, que origina e permite a tensão paradoxal com a homogeneidade greística e abre o campo à visão heraclitiana da harmonia compulsiva, não tendendo para a inércia, mas antes para uma estase permanentemente tensa, como a de um arco curvado por uma corda (Guthrie, 1962, pp. 440-49). A unidade arco-corda e a compreensão do seu poder é o objecto da Lógica.

3. Id (ele, ou isto, em latim) permite-nos, após a adoção freudiana, apelar àquele eu que o próprio eu desconhece mas que o define. 


\subsection{Lógica}

A polissemia da expressão logos, desde a sua origem (Guthrie, 1962, pp. 419-24), é um vestido de palavras para o paradoxo: o nome impronunciável, o saber que não pode ser sabido (Guthrie, 1962, pp. 441-2). O Logos tenta alcançar aquele Absoluto que é, por definição, inalcançável por qualquer consciência parcial; o Superior em si mesmo, que não podemos comunicar e para o qual, segundo Bergson, apenas a intuição serve como prova (Lawlor, 2016). A Lógica - a compreensão possível do Logos - só pode ser percebida de um ponto de vista lato, no território do sentido, como o campo da existência em que qualquer ser se relaciona com o que o transcende - ou seja, com aquilo que não alcança, mas onde está e que o compõe.

No caso humano ser-se é estar-se num quando: um presente-agora que, por ser incongruente com o tempo que permanentemente flui, tem de se manifestar por analogia. Como ser analógico, o Homem comunica a ideia da transcendentalidade de forma mediada e parabólica, com o sentido encontrado num campo anterior ao da narrativa em si mesma, assumindo-se que nessa anterioridade ao Homem existe uma coerência perfeita e um sentido absoluto, dos quais as produções humanas são tentativas de representação e que legitimam referenciais como a verdade ou a justiça (o ser como deve ser) (Voegelin, 2000).

$\mathrm{O}$ evento de horizonte da Lógica é aquele em que, sem razão anterior, se determina que $a$ é $a$ e que $b$ é $b$. É a propriedade da capacidade de determinação de sentido. O elemento necessário ao sentido lógico é, unicamente, uma convergência suficiente de inteligibilidade ao ponto de se criar uma comunicabilidade coerente em que se concorda que $a$ é $a$.

Não é relevante, para o entendimento do poder, se o transcendente é real ou uma mera patologia da mente humana. O poder lógico gera-se a partir dessa crença na autoridade da anterioridade, e traduz-se numa segmentação parabólica do tempo em narrativas que permitam uma perspetiva biográfica do mundo - na constituição, por analogia e partindo de uma ideia de bios (da vida como episódio temporal e não apenas como $z \hat{e} \hat{e}$, que é o prolongamento físico), de histórias que têm um princípio, um meio, um fim e um sentido.

A ação lógica ao alcance do Homem é, assim, a procura de uma estase temporal que permita a fixação da sua representação do transcendente. Circunscreve o tempo e permite ao Homem a anatopia, que podemos definir como a capacidade de gerar localizações do tipo mundo de forma paralela, simultânea e abstraída. A partir da anatopia e da aptidão para aceder à razão profunda - à crença, à intenção, ao amor - o ser humano consegue criar paratopias, loci de poder autónomo e de carácter utópico (ou distópico) suscetíveis de permitir a total fidelização das consciências individuais.

Esta é a ligação da Lógica à Política, pela via ideológica: os indivíduos, que detêm o tempo, tendem a acreditar imediata e absolutamente no mundo que lhes é evidente, e esse mundo ganha um carácter totalitário, soberano e legítimo. O papel que o indivíduo representa, enquanto persona (máscara), ganha carácter de realidade e o sentido da existência individual é determinada pelo mundo em que ele (se) representa (Correia, 2012, pp. 65-84). 
Quadro 1 - Conceitos correlativos entre Greística, Idística e Lógica

\begin{tabular}{|c|c|c|c|}
\hline & Greística & Idística & Lógica \\
\hline \multirow{7}{*}{ 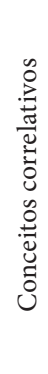 } & $\begin{array}{c}\text { Princípio da Naturalidade } \\
\text { - Ser como elemento } \\
\text { determinado e gregário }\end{array}$ & $\begin{array}{l}\text { Princípio da Propriedade } \\
\text { - Ser como elemento } \\
\text { consciente e individual }\end{array}$ & $\begin{array}{c}\text { Princípio da Temporalidade } \\
\text { - Ser como intérprete e agente } \\
\text { temporal }\end{array}$ \\
\hline & Physis & Ego & Bios \\
\hline & Homogeneidade & Heterogeneidade & Normalidade \\
\hline & Comunidade & Identidade & Sociedade \\
\hline & Igualdade & Liberdade & Equidade (contrato) \\
\hline & Necessidade & Conflito & Convenção (cultura) \\
\hline & Informação & Alienação & Linguagem \\
\hline
\end{tabular}

Fonte: Do autor (2019)

\section{Estase - O Poder Tridimensional Segundo o Homem}

Cada uma das três dimensões de leitura temporal tem, para o Homem, uma capacidade genética de poder, que, visto individualmente, não faz sentido, mas que se completa numa mutualidade que iremos definir como estase temporal da possibilidade: uma detenção sincrética, modal e simbiótica das relações de poder entre todas as possibilidades ao alcance do Homem. Politologicamente, Greística será a região dos agregados, Idística a região do outro e a Lógica a região do sentido. A síntese antropológica do poder faz-se de forma ideológica, e uma ideologia, enquanto engenharia conceptual subsidiária da Lógica, confunde-se com política, pelo que, antes de se definir ideologia, é necessário esclarecer a política.

\subsection{O Vício Politológico}

A hipótese política é vulgarmente pensada como um ponto de encontro entre greísmos e idísmos. Deste germe mental provém, quanto a nós, a erroneidade da teoria política no que respeita ao poder autoritário individual.

\subsubsection{Horizontalidade Normativa e Verticalidade Política}

Na sua dimensão greística, o indivíduo pertence ao tempo e é formalmente determinado por ele; em termos idísticos, o indivíduo é proprietário do tempo e determina a sua forma. Nas relações greísticas de poder o indivíduo depende de um tempo comum; nas relações idísticas de poder o tempo depende da propriedade ontológica de qualquer indivíduo para emergir como real. Daqui resulta a primeira oposição entre greísmo e idísmo: o poder greístico compele à isonomia e o poder idístico impõe a autonomia.

O conceito greístico fundamental para a politologia é o da necessidade, entendendo-se esta como uma condição própria, obrigatória e inevitável, segundo a qual qualquer tipo de agregação obedece a uma ordem física, que tanto podemos chamar 
de informação como de código ou de natureza. A idística é o conflito, que vai da supressão máxima de uma coisa por outra à coexistência não-supressiva entre uma coisa e outra.

Greísmo é comunidade e desapropriação da consciência monádica por uma determinação que é igual para todos. O indivíduo é apenas um como os outros, e o todo é visto como-um, homogéneo. Idísmo é individualidade e propriedade; uma identidade irredutível que permite a intencionalidade operante, se quisermos adotar a linguagem fenomenológica de Husserl (Beyer, 2016).

O campo de sobreposição entre o indivíduo e a comunidade resulta na constituição de um ethos que, originalmente, tem de ser visto como a área dos costumes (mores) e do habitus. A Política surge como uma proposta de normatividade ética razoável, tentando conciliar a isonomia e a autonomia num híbrido equidade que permitiria não uma abdicação mas antes uma sujeição do eu ao os que são como eu.

Essa protopolítica pode ser visualizada de uma forma simples:

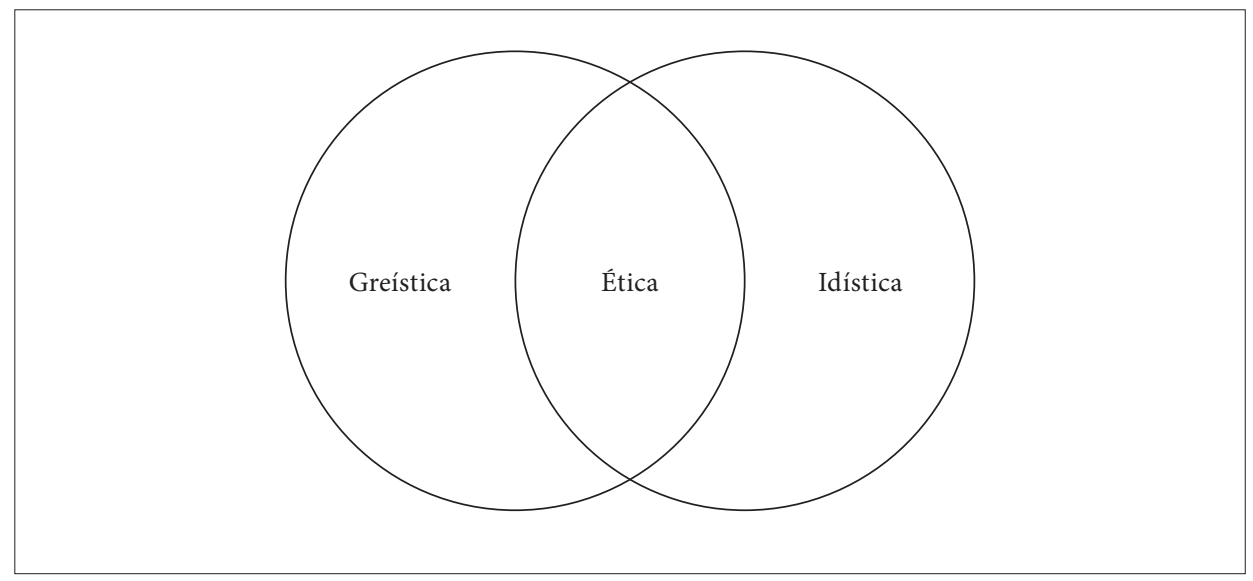

Diagrama 1. Protopolítica

Fonte: Do autor (2018).

A política inicia-se na retilinearidade, mas é na verticalidade, mais do que na horizontalidade linear, que se encontra a sua distinção lógica ${ }^{[4]}$. Na lógica política humanizamos o azimute arquitetando-o. Passamos da montanha mais alta, como resumiu Mircea Eliade, à coluna, trazemo-la para o templo e para as oikoi, que, circunscritamente ordenadas, constituem a polis. Esta será o produto da arte normativa

4. Algo difícil de compreender pelos Romanos que, apesar da verticalidade, tiraram do esquadro grego (nomos) sobretudo a horizontalidade básica, o que também ajudará a explicar a tradução de politeia como res publica, por Cícero, assim como a diferença entre a civilização pelas leis e a civilização pelas ideias (Prélot e Lescuyer 2000, 109-123) 
geométrica, enquanto a política se torna na arte da representação da geometria pela construção (Prélot e Lescuyer, 2000, pp. 47-52). A cidade é o que ascende, verticalizando-se. É teológica, e a política religiosa.

A hipótese de transcendência pela política não se legitima, assim, apenas pela abstração da elevação pessoal. Na síntese do zôon politikon (Aristóteles, 1984, 4268) Aristóteles tenta conjugar todas as dimensões de um ser humano que já não é apenas um como os outros mas alguém, apto a viver bem, por uma ideia de justiça que, greisticamente, não seria necessária, podendo facilmente ser substituída pelo direito.

A consciência do justo requer um papel idístico. Quem ascende de déspota a cidadão é o indivíduo consciente, que retira a ética do plano meramente determinativo da física e a recoloca sob alternativa, dando-lhe a possibilidade de moralização pelo equilíbrio - o jus (Maltez, 2007, pp. 554-62) (Maltez 1996, pp. 167-71). Criando um sistema que estabiliza a techne normativa perante a krysis socrática (que minimiza o homem a um ponto de ignorância ${ }^{[5]}$ ) a politologia aristotélica transforma o pensamento greístico ecológico ${ }^{[6]}$ num projeto económico. Ao vincular qualquer futuro individual do Homem ao destino da Cidade, Aristóteles unifica a possibilidade e estabelece a base de um poder político totalitário que pode ser desenhado da seguinte forma:

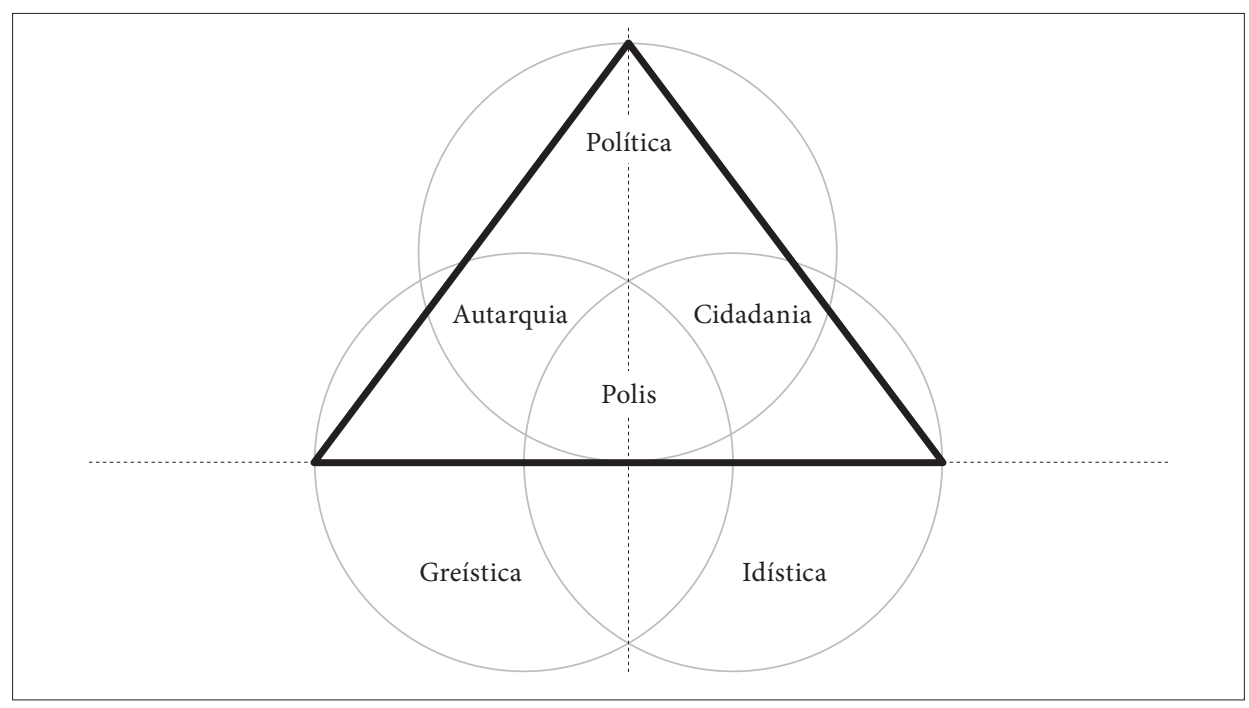

Diagrama 2. A Conceção Original de Política

Fonte: Do autor (2019).

5. O aforismo délfico "gnoti se auton» não é, quando proferido por Sócrates, tão um encorajador "conhece-te a ti mesmo!» quanto um bem mais sardónico «enxerga-te, criatura...»

6. No sentido de uma casa única para todos implicar uma lógica própria e igualmente comum. 


\subsection{A Captura Greística das Ideias}

\subsubsection{O «Tudo é Político»}

O animal político aristotélico é a criatura de um processo civilizacional e a sua premissa de legitimidade é a de que o Homem, como ser noético e com acesso à anima do cosmos por via da intelecção contemplativa, pode atingir a identidade com essa ordem divina (Guthrie, 1962, pp. 6-14). O animal político é, portanto, um ser greístico, uma vez que essa identificação se faz especificamente com a physis, em que o nous clássico se define como uma revelação da Natureza enquanto verdade insofismável.

Essa preentividade da física afasta-o da região da intuição pura do justo, que permite a distinção entre o que Locke chamou de razoabilidade [reasonableness, como sinónimo de fairness, ou justiça (Rawls 1999)] — que é a nossa razão como sensatez, a que os gregos chamavam phronesis e os romanos prudentia (Maltez, 1996, p. 26) e a rationality, que é a área do rácio e da consequencialidade determinável (Maltez, 2014, pp. 361-2). A primeira será a dimensão idística da Lógica, a segunda a sua dimensão greística.

A racionalidade é uma tentativa de sincronização com o tempo físico. A ratio pitagórica (Guthrie, 1962, pp. 212-52) não pretende apenas ser uma chave para o enigma da physis: ela ensaia a sobrevivência ao tempo. A matemática, enquanto linguagem de um «se... então», ganhou uma legitimidade de representação da verdade absoluta que se manteve até hoje e que é decisiva para a confusão entre governo e política, função e representação.

A premissa de que o Homem-espécie pode compreender o mundo permite a ideia de que o pode circunscrever totalmente (incluindo os seus fins e o seu sentido) e que é o tempo que lhe pertence em vez do contrário, abrindo-se o caminho para o totalitarismo da política racionalista sobre a própria realidade: a política torna-se na ciência do poder greístico (o poder absoluto, como determinação) e o político numa simplificação ética de lógica meramente adversativa, em que a instituição não permite o indivíduo excepto se, e vice-versa:

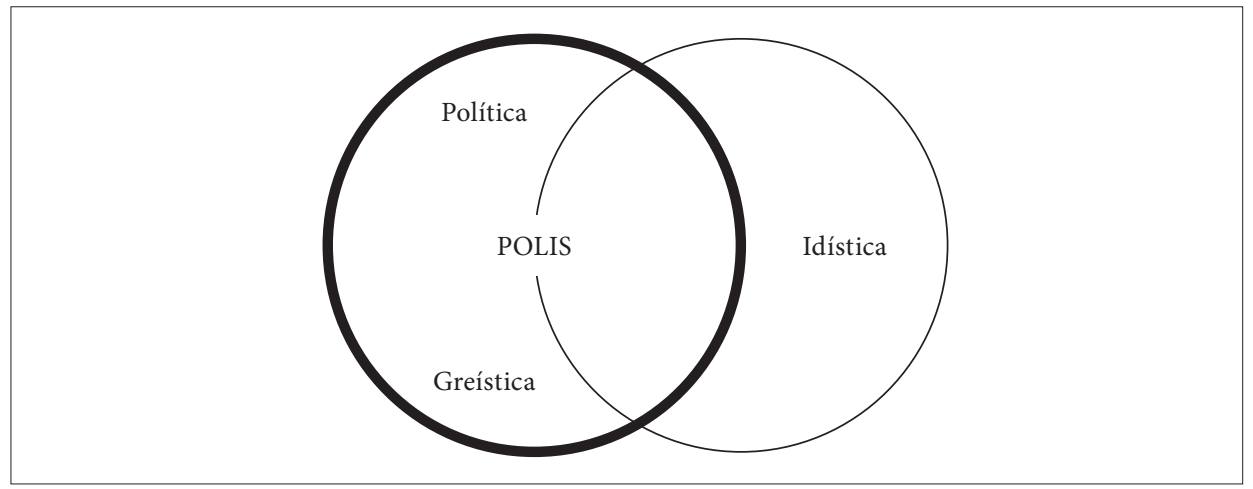

Diagrama 3. A Conceção Greística da Política 
Só partindo desta visão plana, faz sentido entender como conceito fundamental do político a possibilidade de constituição de uma relação amigo-inimigo, tal como a entendeu Carl Schmitt (Schmitt, 2015), e, partindo daí para uma conceção de poder como imperium, limitar a soberania a uma decisão sobre o que é normal e o que é excecional, tornando-a num exercício de homogeneização que consiste, basicamente, na normalização sistemática da entropia dentro da sua área de jurisdição.

Nesta perspetiva a essência da política seria a segregação normativa: uma ação exclusiva e negativa, baseada na guetização da diferença, executada por um Estado com razão e ética próprias e em que o momento mais importante é o da constituição de uma temporalidade específica em que se decide quem é «membro» e quem é «estranho» (Walzer, 1999, pp. 46-56), quem pode fazer o quê, como e quando.

É também nesta sobreposição entre greística e política que se transforma o animal político num bicho político. Ao interpretá-lo como zôon - tal como Aristóteles o fez, ainda que pareça já claro, como refere Agamben, que essa expressão tenha sido utilizada mais por questões linguísticas que por ordem de rigor (Agamben, 1998, pp. 11-2) - estamos a restringir vida a algo não muito diferente de um ato sucessivo de contração e descontração pulmonar e a considerar a política como uma continuação da respiração por outros meios. Nesta perspetiva a política só poderia ser vista como uma biopolítica, e o corpo físico humano como seu objeto sagrado (Agamben, pp. 1998).

No entanto, fica claro, logo em Platão e Aristóteles, que o homem político não se situava já na $z \hat{o} e$, mas na bios (Agamben, 1998, pp. 11-2). A alma do animal político não é biológica mas biográfica, porque o Homem, para os antigos e para os modernos, é o animal da palavra (Maltez, 1996, 331-3). A bios é preenchida pela narrativa, não pelo oxigénio, e é por isso que também é possível afirmar, como Voegelin, que só há política onde há História (Voegelin, 1982).

\subsection{2 $\mathrm{O}$ «Em Tudo Há Política»}

A captura greística da lógica faz-se através das ideias de função e de organização, sendo essa a verdadeira sublimação aristotélica em relação à tradição do seu tempo. Nessa linha, a ligação do Homem à Natureza será a sua constituição orgânica. Ela é necessária e integralmente composta, por partes operativas com funções determinadas que a mantêm animada e que só funcionam em conjunto. O objetivo orgânico é a sobrevivência do próprio organismo como um todo e, nessa evidência, Aristóteles encontra o princípio básico que servirá de justificação a todo o processo totalitarista: o todo é mais importante do que as partes, porque as partes existem para o todo e não o inverso. A polis, como todo soberano de ordem superior e como organização de todas as partes que a compõem com vista à autarcia, seria, zoologicamente, o valor supremo.

A ideia da superioridade natural do todo sobre as partes, já reclamada por Platão via Sócrates (Platão s.d., 71), aplicada a uma conceção greística da realidade, legitima a amputação do poder autoritário ao agente individual. A partir desse princípio é 
possível dizer que em tudo há política, uma vez que todo o sentido da existência no mundo humano e toda a vita activa, como a designou Hannah Arendt (Arendt 2001, 19-39), desemboca no mar político. A circunscrição do poder político passa a ser universal e a função decisória transforma esse poder político num poder-sobre que é sobre tudo o resto:

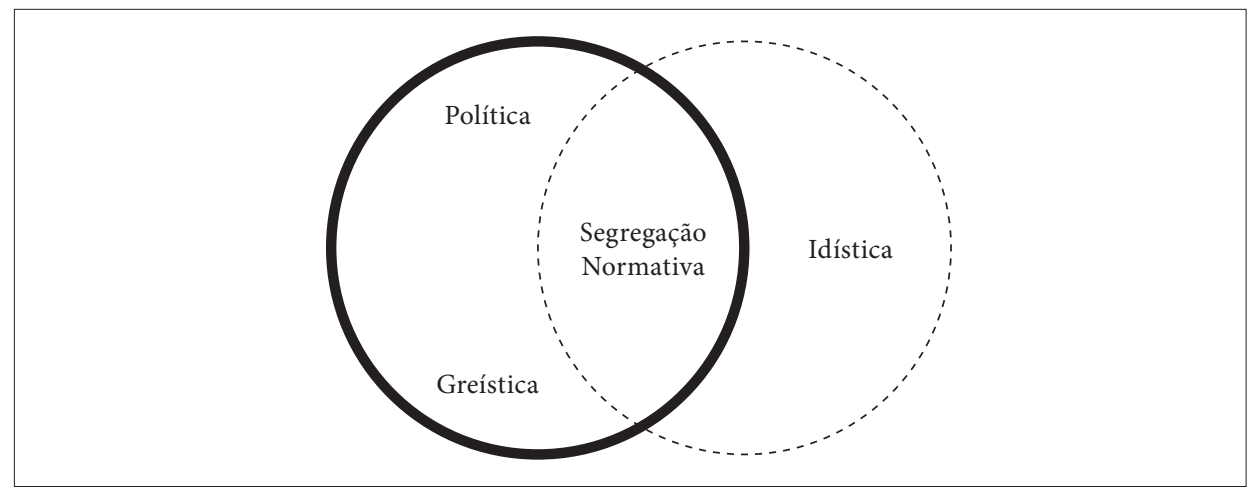

Diagrama 4. O Totalitarismo Greístico da Política

Fonte: Do autor (2019)

O fundamental, no âmbito deste estudo, é aceitar que essa ideia de superveniência do todo sobre as partes não decorre de uma leitura indiscutível do mundo, mas antes de uma visão parcial, dogmática e voluntarista da realidade. A ideia de as partes não fazerem sentido sem o todo é simétrica, em termos lógicos, à de o todo não existir sem as partes e de não fazer sentido sem elas, pelo que a existência do todo é tão importante como a de cada parte. Este é o ponto realmente relevante na teoria monádica do poder, porque apenas partindo dele a redescoberta moderna da consciência individual, a perceção da inevitabilidade da diferença e a recuperação da crítica permitem a cura da miopia antagónica, diádica e totalitária da política.

\subsection{Hipostasia - A Possibilidade Ideológica}

Uma interpretação mais correta das relações de poder no mundo humano apresentar-se-ia da seguinte forma: 


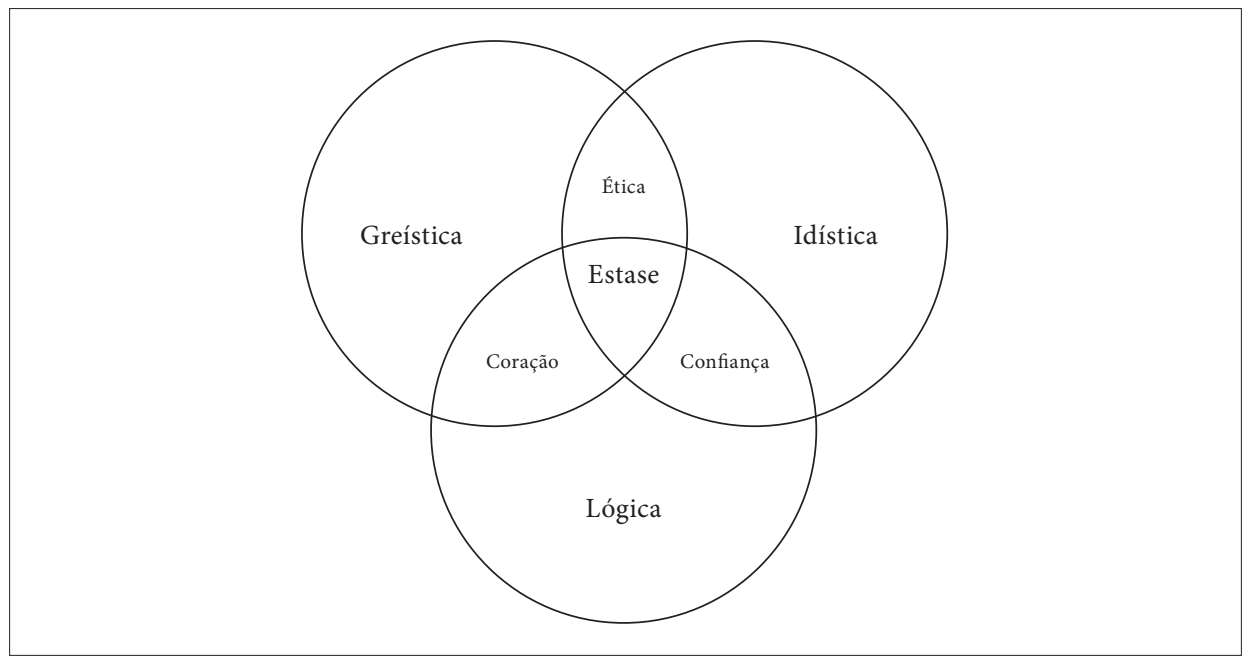

Diagrama 5. Estase do Poder

Fonte: Do autor (2019).

\section{Sendo que:}

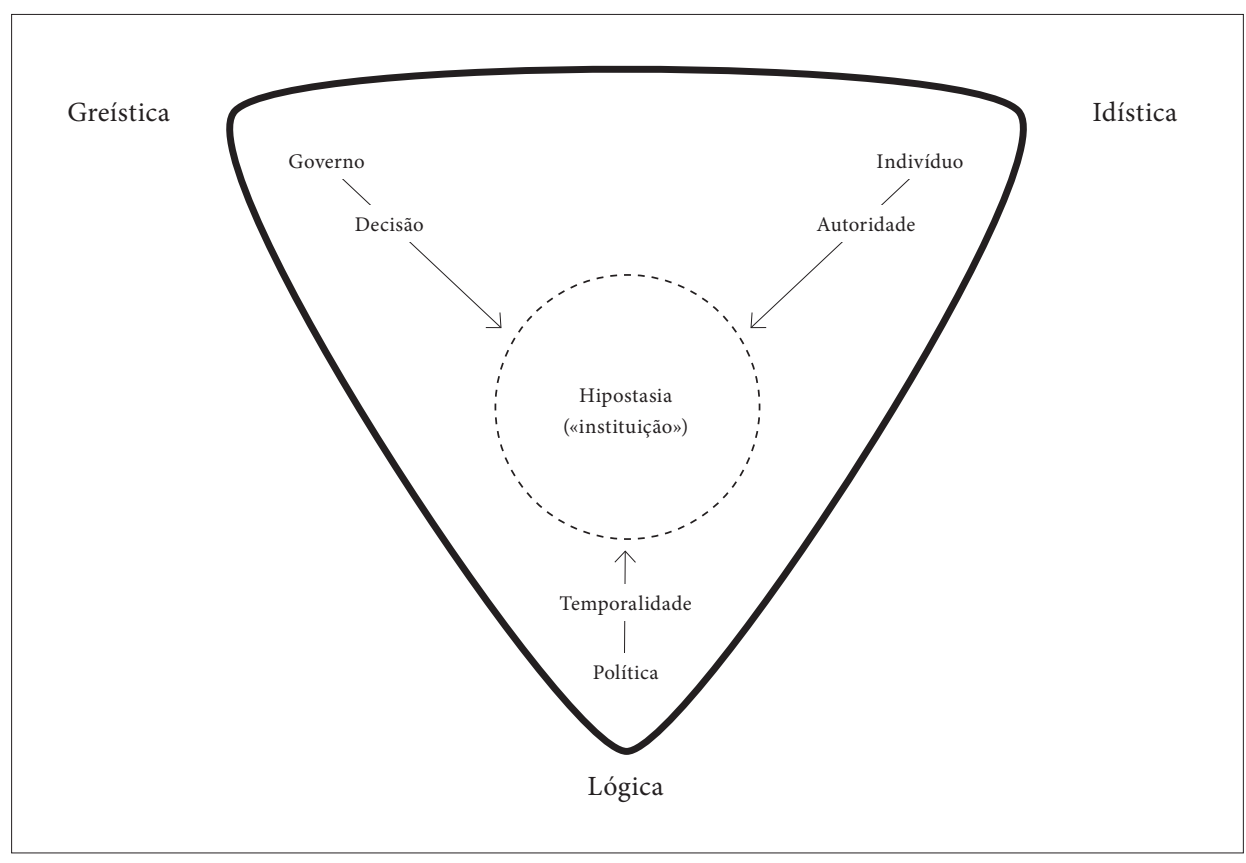

Diagrama 6. Dinâmica da Estase do Poder

Fonte: Do autor (2019). 
A coesão eidética, sustentada pela crença numa coerência absolutamente resiliente que permite o estabelecimento de um jus (chamemos-lhe fé), é uma função lógica de circunscrição temporal-tópica dentro de um campo de infinitude greística que, de outra forma, seria ininteligível.

A ideologia será a passagem à práxis desse consenso pela fidelização - de forma devotiva —, sobre um topos de homogeneidade, e a inteligibilidade antropológica resultará em sucessivas tentativas de detenção temporal por parte do Homem; de uma suspensão da dinâmica por parte de um ser que precisa de estar num ambiente em que nada está e tudo vai estando - porque, nas palavras de Bergson, "a nossa inteligência procura fixação por todo o lado». (Bergson, 1946, p. 14)

A ideologia, que dá azo à política (e não o inverso), será uma construção autónoma e essencialmente tautológica de representação de uma anterioridade, sem carência de legitimação extrínseca, que tenta conjugar uma alternativa tão unânime quanto possível como resposta à condição humana - àquilo que Espinosa, referindo-se às «afeções da alma», resumiu como os desejos e os medos (B. Espinosa, 2007, p. 3) (B. Espinosa, 1992, pp.263 e segs.), e que se pode sintetizar na esperança.

Ao propor um presente perpétuo e previsível, ainda que paratópico, sob a forma de uma normalidade que literaliza o passado e pretende fixar o tempo pela antecipação do futuro, a ideologia apresenta aos indivíduos uma hipótese de agregação através de uma estase temporal, que, recorrendo a uma instituição (como positum) do poder (Hauriou, 1970), mitigue a coação da ordem natural e a imprevisibilidade do conflito idístico.

O resultado é uma hipostasia distópica que almeja à dogmatização numa unidade biográfica coerente - numa nação, por exemplo. Distópica porque o seu fim conceptual é uma reificação de um estado de coisas que não passa de uma degeneração aporética da estase: o ponto de situação, o estado a que se chega (Maltez, 2007, pp. 569-81), encontra-se num presente que, sendo tudo o que o Homem pode tomar como certo, é o único momento que o tempo não tem (Reis, 2007, pp. 798-801).

Assim, a utopia (que, neste ponto, já é sempre uma distopia) não é apenas possível: ela é real, e a prova da utopia é a contemporaneidade (Carvalho, 2000), qualquer seja.

\subsection{Governo vs. Política}

O Estado perpetua-se entre a coagulação e a dissolvência lógica de um determinado preenchimento, procurando em permanência um ponto de suspensão convencional. Na contemporaneidade, o seu problema mais atual é o da fronteira entre governo e política: as ideologias hegemónicas procuram a legitimação através da conjugação de kratos com hierarquia, e consomem-se na procura de um melhor regime para a razão, sem conseguirem fazer a distinção essencial entre res publica e polis (Maltez, 2014, pp. 346-7; 382) (Maltez, 1996, pp. 336-40)

Como coisa de todos, a república é um conceito greístico, que aceita a ideia de agregação e de autarcia perante as leis naturais. Em termos republicanos, a legitimidade das instituições decorre do bom emprego do poder. O governo é a função da 
República, e governar é decidir. A decisão é uma tentativa de sincronização sistémica, e funciona ciberneticamente, conforme a conhecida teorização de Deutsch, por tentativa e retroação (Deutsch, 1965).

A política, enquanto gesto ideológico, tem uma função meramente representativa, de expressão analógica da anterioridade. A circunscrição do político, no Estado, não é a da autoridade, que é idística, nem a decisória, que é greística, mas a da representação. A ação política de facto dá-se sempre que há a possibilidade da dissensão utópica e da transposição, para uma contemporaneidade, de subjetividades como a justiça ou a liberdade.

A expectativa política que recai sobre o Estado é a de mediar entre a visão teológica criadora da utopia e a própria utopia reificada (Voegelin, 2000), e a crise política do Estado ocorre quando este deixa de conseguir mediar os valores fiduciários consensuais e passa a representar-se a si mesmo como valor mais valioso. Sendo a política um processo discursivo puro, hermético, autopoiético (Maltez, 2014, p. 27), não-expansivo e, logo, inconsequente, ao assumir-se como real a totalitarização política do poder transforma a hipóstase num estado temporal próprio - numa realidade paralela. A prima ratio da função institucional passa a ser o próprio soberanismo que não é mais do que a superiorização valorativa ad eternum do Estado-função, o que resulta na nihilização e na falsificação da política, por ausência de objeto de representação.

\section{Conclusão}

Foi necessário todo o processo de desmaterialização da autoridade descendente no Ocidente para abrir espaço à aceitação de um mónada consciente como fonte autoritária de poder.

A desmistificação do corpo humano e a sua vulnerabilização ecológica e psicológica são o atual ponto de confronto, pós-moderno, com o ainda hegemónico dogma do valor sagrado da vida orgânica humana, ou com outro, o da superioridade natural do ser humano sobre o mundo. A história da modernidade é a história do confronto da ideia de liberdade, pró-idística, com o totalitarismo de base do greísmo, mas a crise do Homem contemporâneo é já uma crise de identidade individual que permite falar, até, em psicopolítica (Han, 2014).

A emergência e resiliência do poder monádico resulta de uma relocalização temporal do indivíduo, nomeadamente a partir do momento em que o cidadão se torna socium (Maltez, 1996, pp. 294-6): alguém já detentor da prerrogativa do juízo, da prudentia, que lhe permite ou unir-se, em contrato, a um negócio comum, ou rejeitá-lo. O poder do cidadão-sócio é, então, simultâneo ao da república e antecedente ao da política. Em relação à ordem greística, o indivíduo é igual. Em relação à ideologia, concretiza a autoridade através da proximidade relativa à verdade, que só ele pode intuir.

A subsidiarização da política em relação ao indivíduo dá-se no momento em que se aceita que o indivíduo está antes da instituição ideológica, e que a propriedade antecede a edificação. Em sentido inverso, a captura do cidadão pela política ocorre 
quando a propriedade sobre o tempo é retirada ao indivíduo, o que ocorre, vulgarmente, por meio de uma reconstituição cultural filogenética através da qual a mediação ideológica convence o indivíduo de que:

a) O único tempo que existe é o tempo greístico, homogéneo;

b) A política é a única forma de conciliar a temporalidade própria do indivíduo — o seu ciclo de vida, as suas expectativas, o seu sentido de justiça e do verdadeiro - com o tempo greístico e que isso se faz, inevitavelmente, por um processo de normalização ética em que o ser autónomo se encerra numa máscara (numa personagem representativa que atua dentro de parâmetros narrativos pré-determinados, normais, inteligíveis e coerentes), prescindindo da autoridade em favor da representação e da propriedade em favor da utilidade.

A deriva pós-totalitária das ideologias hegemónicas conduz o indivíduo à convicção de que esta captura é inevitável. Este processo mental, contudo, não altera a premissa fundamental do poder monádico: como proprietário do tempo o indivíduo tem uma autoridade prévia e, portanto, superior ao tempo ideológico - ele é um autor antes de ser um ator. É por essa razão, cremos, que o poder monádico apresenta uma compulsão irreprimível para a manifestação politicamente subversiva, sobretudo em contextos em que as pessoas, devidamente informadas e mesmo com todas as razões para aceitarem a normalidade, não se conformam.

Data de receção: 31/01/2018

Data de aprovação: 20/11/2019

\section{Referências}

Agamben, G. (1998). O Poder Soberano e a Vida Nua. Lisboa, Portugal: Editorial Presença. Arendt, H. (2001). A Condição Humana. Lisboa, Portugal: Relógio D’Água.

Aristóteles (1984). Politics. In J. Barnes (Ed.) The Complete Works of Aristotle (4265-4568). Princeton, NJ: Princeton University Press.

Bergson, H. (1946). The Creative Mind. New York City, NY: The Philosophical Library.

Beyer, C. (2016). Edmund Husserl. The Stanford Encyclopedia of Philosophy. https://plato. stanford.edu/archives/win2016/entries/husserl/ (acedido em 3 de Novembro de 2017).

Carvalho, A. D. (2000). A Contemporaneidade como Utopia. Porto, Portugal: Edições Afrontamento.

Clément, E., Demonque, C., Hansen-Love, L. \& Kahn, P. (1997). Dicionário Prático de Filosofia. (2. ${ }^{\mathrm{a}}$ ed). Lisboa, Portugal: Terramar.

Correia, C. J. (2012). Sentimento de Si e Identidade Pessoal. Lisboa, Portugal: Centro de Filosofia da Universidade de Lisboa.

Deutsch, K. (1965). The Nerves of Government. New York City, NY: The Free Press.

Espinosa, B. (1992). Ética. Lisboa, Portugal: Relógio d’Água. 
Espinosa, B. (2007). Teological-Political Treatise. New York City, NY: Cambridge University Press.

Guthrie, W.K.C. (1962). A History of Greek Philosophy: The Early Socratics and the Pythagoreans. Vol. I. Cambridge, Reino Unido: Cambridge University Press.

Foucault, M. (2000). Power. New York City, NY: The New York Press.

Habermas, J. (2005). The Philosophical Discourse of Modernity. Malden, MA: Polity Press.

Han, B. (2014). Psicopolítica: Neoliberalismo y Nuevas Técnicas de Poder. Barcelona, Espanha: Herder.

Hauriou, M. (1970). The Theory of the Institution and The Foundation - A Study on Sovial Vitalism. In A. Broderick (Ed.), The French Institutionalists: Maurice Hauriou, Georges Renard, Joseph T. Delos, (93-124). Cambridge, MA: Harvard University Press.

Husserl, E. (2008). Introduction to Logic and Theory of Knowledge - Lectures 1906/07. Dordrecht, Países Baixos: Springer.

Husserl, E. (2013). Meditações Cartesianas e Conferências de Paris. Rio de Janeiro, Brasil: Editora Forense.

Lawlor, L. (2016). Henri Bergson. The Stanford Encyclopedia of Philosophy. <https://plato.stanford.edu/archives/sum2016/entries/bergson/> (acedido em 5 de Novembro de 2017).

Leibniz, G. (2016). Monadologia. Lisboa, Portugal: Edições Colibri.

Look, B. C. (2017). Gottfried Wilhelm Leibniz. The Stanford Encyclopedia of Philosophy. <https://plato.stanford.edu/archives/sum2017/entries/leibniz/> (acedido em 1 de Dezembro de 2017).

Maltez, J. A. (1996). Princípios de Ciência Política: Introdução à Teoria Política. Lisboa, Portugal: Instituto Superior de Ciências Sociais e Políticas.

Maltez, J. A. (2007). Metodologias da Ciência Política: O Estado à Procura do Político. Lisboa, Portugal: Instituto Superior de Ciências Sociais e Políticas.

Maltez, J. A. (2014). Abecedário de Teoria Política - Ideias e Autores dos Séculos XIX e XX. Vol. I. Lisboa, Portugal: Instituto Superior de Ciências Sociais e Políticas.

Platão (s.d.). A República. (14. ${ }^{\mathrm{a}}$ ed). Lisboa, Portugal: Fundação Calouste Gulbenkian.

Prélot, M. \& Lescuyer, G. (2000). História das Ideias Políticas. Vols. I. e II. Lisboa, Portugal: Editorial Presença.

Rawls, J. (1999). A Theory of Justice: Revised Edition. Cambridge, MA: The Belknap Press of Harvard University Press.

Reis, J. (2007). Sobre o Tempo. Porto, Portugal: Edições Afrontamento.

Schmitt, C. (2015). O Conceito do Político. Lisboa, Portugal: Edições 70.

Voegelin, E. (1982). A Nova Ciência da Política. Brasília, Brasil: Editora Universidade de Brasília.

Voegelin, E. (2000). The Political Religions. New York City, NY: University of Missouri Press. Walzer, M. (1999). As Esferas da Justiça. Lisboa, Portugal: Editorial Presença. 


\section{Sobre o autor}

HUGo ALEXANDre LEAL nasceu em Lisboa a 20 de Maio de 1974. É licenciado e estudante de doutoramento em Ciência Política pelo Instituto Superior de Ciências Sociais e Políticas da Universidade de Lisboa, onde também concluiu uma pós-graduação em Governance e Strategic Intelligence. A Filosofia Política é a sua área preferencial de estudos, nomeadamente os temas da liberdade, do poder individual e da justiça. Publicou o artigo O Voto Justo: Questões sobre um Sufrágio Equitativo no número 8/17 da Revista Portuguesa de Ciência Política.

\section{About the author}

HUGO ALEXANDRE LEAL was born in Lisbon on May 20, 1974. He holds a degree and is currently a PhD student in Political Science at the Higher Institute of Social and Political Sciences of the University of Lisbon, where he also completed a postgraduate degree in Governance and Strategic Intelligence. Political philosophy is his preferred area of study, namely the themes of freedom, individual power and justice. He published the article The Fair Vote: Questions on Equal Suffrage in issue 8/17 of the Portuguese Journal of Political Science. 